\title{
KEY SAFETY APPROACHES IN BANGLADESH RAILWAY
}

\author{
Hasib Mohammed Ahsan \\ Department of Civil Engineering, Bangladesh University of Engineering and Technology, Dhaka, Bangladesh
}

Received: 07 May 2019

Accepted: 25 February 2021

\begin{abstract}
Bangladesh Railways (BR) is an integral part of the country's transportation system since the British era. At present it covers a length of 2,877 route kilometres. Train accident data collected from BR revealed that train accidents reduced from 590 per year for 2001-10, to 250 per year for 2010-2015 and to 166 for 2015-16. Data also shows that derailments are the major concern in railway safety. Mixed railway gauges, rail weight, battered and damaged rails, low sleeper density and damaged sleepers, lack of maintenance of fittings and fastenings, and inadequate amount of ballasts are the main reasons for such derailments. So as a safety approach against derailments BR has taken rail track rehabilitation projects as well as speed restriction programs. 2015-16 data showed benefit of such restriction program. A speed map is prepared according to the speed restriction program and speed capacity of different sections of the railway network.
\end{abstract}

Keywords: Safety approach, Speed map, Speed restriction, Train accident.

\section{INTRODUCTION}

Increasing demand for transport, increasing road congestion, increasing concern over safety and environmental matters, and technology-led cost reductions have given rising interest in railways for inter-urban, urban and even rural transport services. Many countries, both in the developed and developing worlds, are finding that rail transport is cost effective at meeting some of the growth in demand through the construction of new lines or more effective and efficient use of existing lines and services as well as provides a safe, efficient means of transport with minimal environmental impact (Godward, 1992). Though, railway transportation system is recognized as a safest mode of land transport around the world, railway accident has always been the major challenge for rail safety as well as a point of attention to the engineers and researchers (Agarwal, 2005, 2007; Brabie, 2005; Wu and Wilson, 2006). Moreover, rail accident is not the result of a single cause but the combination of several contributory factors, which are associated with the rail users, the vehicle, the track and the rail environment (Ahsan et al., 2014c). It is therefore, important in our context to understand the overall accident problem so as to be able to reduce accident and thereby improve the safety environment of rails.

Bangladesh Railway (BR) has been experiencing a large number of train accidents since its development in 1972 (Ahsan and Islam, 2015). Disruption to services, substantial financial losses and safety risk to staff and passengers are highly obvious from such occurrence (Barkan et al., 2003). However, very few researches have been carried out regarding train accidents in Bangladesh to determine the underlying causes for the development of effective countermeasures to enhance railway safety. This paper thus attempts to investigate accident data in the light of accident classification, accident distribution, accident factors and accident casualties as well as investigates the effectiveness of the safety approaches of Bangladesh Railway in this regard.

\section{ACCIDENT DATA ANALYSIS}

\subsection{Train Accidents}

A train accident is termed as any occurrence which does or may affect the safety of the railways, its engine, rolling stock, permanent way, works, passengers or servants which either does or may cause delays to trains or loss to the railways (Arora and Saxena, 2006).

Data collected from Bangladesh Railway revealed that train accidents reduced from around 590 per year for 200110 , to around 250 per year for 2010-2015 and to 166 for 2015-16 (BR, 2009-2016). These accidents are presented according to accident classification, accident distribution, accident factors and accident casualties in the following sections. 


\subsection{Accident Classification}

Accidents are classified into three major groups with a total of ten types as shown in Table 1. Derailments are the highest type of accident around 90 per cent of the total incidence (Ahsan et al., 2014b). However, 2015-16 data showed a reduction of derailments to 74.1 per cent.

Table 1: Accident Classification

\begin{tabular}{|c|c|c|c|}
\hline \multicolumn{3}{|c|}{ Accident Classification (Types) } & Percent \\
\hline \multirow[t]{4}{*}{ (A) Accident to trains: } & (1) Collision & a. Passenger trains & 5.0 \\
\hline & & b. Other trains & 1.7 \\
\hline & (2) Derailment & a. Passenger trains & 20.2 \\
\hline & & b. Other trains & 22.0 \\
\hline (B) Fires: & (1) Fire in train & & 0.2 \\
\hline \multirow[t]{8}{*}{ (C) Other accidents: } & (1) Trains runni & ig over cattle on the line & 0.0 \\
\hline & (2) Train runnir & $\mathrm{g}$ into road traffic at level crossing & 0.0 \\
\hline & (3) Train runnir & g over obstruction not covered in 1 and 2 & 0.2 \\
\hline & (4) Derailment & f vehicles in yard & 41.0 \\
\hline & (5) Derailment & f light engines & 6.6 \\
\hline & (6) Bursting of & oints & 1.3 \\
\hline & (7) Averted col & sion & 1.9 \\
\hline & & & 100.0 \\
\hline
\end{tabular}

\subsection{Accident Distribution (Departments held responsible)}

Bangladesh Railway had allocated accidents considering responsibilities of various departments involved in railway services according to their internal process as shown in Table 2.

Table 2: Accident Distibution

\begin{tabular}{lr}
\hline Departments held responsible & Percent \\
\hline (1) Traffic department & 8.8 \\
(2) Engineering department & 12.7 \\
(3) Mechanical department & 17.7 \\
(4) Signal and Traffic department & 1.2 \\
(5) Engineering and Traffic department & 0.7 \\
(6) Engineering and Mechanical department & 2.5 \\
(7) Traffic and Mechanical department & 1.7 \\
(8) Other departments & 8.9 \\
(9) Pending & 45.8 \\
& 100.0 \\
\hline
\end{tabular}

\subsection{Accident Factors (Causes)}

The total train accidents were attributed by human elements, technical defects and other causes. Table 3 shows that other causes consist of the highest share of 47 per cent. This is perhaps due to weak reporting system. However, there is a sudden change in 2015-16 reporting with human elements as 84.94 per cent, technical defects as 10.84 per cent and other causes as remaining 4.22 per cent.

Table 3: Accident Factors

\begin{tabular}{llr}
\hline Accident Factors (Causes) & Percent \\
\hline (A) Human elements & (1) Breach of rules, wrong manipulation of block & 6.2 \\
& instruments and setting of points, etc. & \\
& (2) Passing of signal at danger & 4.5 \\
& (3) Breach of rules by Locomotive Masters and Assistant & 15.2 \\
& Locomotive Masters & \\
(B) Technical defects & (1) Engines & 1.4 \\
& (2) Vehicles & 8.7 \\
& (3) Tracks & 14.9 \\
& (4) Signaling and interlocking apparatus & 0.7 \\
(C) Other causes & (5) Other technical defects & 1.4 \\
& (1) Miscellaneous & 47.0 \\
& & 100.0 \\
\hline
\end{tabular}


Track condition causes the highest accident reflecting technical defects. Mixed railway gauges (BG, MG \& DG), rail weight ( $75 \& 90 \mathrm{lbs}$ ) and wear (battered, damaged, increase in friction and expansion gap), inadequate amount of ballasts, sleeper materials and density, and lack of appropriate fastenings are found to be the weaknesses of railway track (Ahsan et al., 2014a).

\subsection{Accident Casualties}

Table 4 shows percentage of killed and injured for passenger, railway employees and other persons.

Table 4: Accident Casualties

\begin{tabular}{lcc}
\hline & \multicolumn{2}{c}{ Casualties (Percent) } \\
\hline & Killed & Injured \\
Passenger & 12.8 & 37.5 \\
Railway Employees & 1.3 & 9.2 \\
Other Persons & 8.3 & 30.9 \\
& 22.4 & 77.6 \\
\hline
\end{tabular}

\section{SAFETY APPROACH}

Around the world, railways have come to be recognized as a safest mode of mass transportation because of its inherent characteristics. Therefore, safety becomes the foremost issue while transporting man and materials in railway system. To ensure railway safety around the world all the activities includes according to the three-tier approach as follows (Rail Safety New Zealand, 2011).

\subsection{Education}

Education includes (i) Advertising, (ii) Publicity and media relations, (iii) Awareness raising events and campaign, (iv) Development of education resources for schools (v) Publication and display of rail safety pamphlets brochures (vi) Training, etc.

\section{2 $\quad$ Engineering}

Engineering includes (i) Ensuring structural and functional integrity of the infrastructure and its subsystem (Track improvements, periodic maintenance, level crossing up gradation, Enhanced track inspection technology etc.), (ii) Ensuring structural and functional integrity of the rolling stock, (iii) Ensuring appropriate operational procedures and information management for effective train handling etc. (improved signaling and interlocking system).

\subsection{Enforcement}

Enforcement includes (i) Application of appropriate warnings or prosecution against those who fail to obey the rules and regulations. However, Bangladesh Railway has considered speed restriction as the most effective safety measure against derailments. Some rail track rehabilitation projects along with modernization of signal interlocking system are also in the process.

\section{MAXIMUM SPEED AND SPEED RESTRICTIONS}

Permissible line speed is the maximum speed at which trains may operate on a track. It is also called maximum allowable speed or allowable speed. Each route section has a published speed limit which will vary locally according to track and route features such as junctions where trains pass between different routes (Bangladesh Railway, 2016). There are two types of speed restrictions.

\subsection{Temporary speed restriction}

Due to engineering works, a temporary speed reduction (TSR) may be enforced at a particular location. Temporary Speed Restrictions apply to all other conditions not covered by the permanent timetable including track defects, line side hazards and maintenance works. 


\section{2}

Permanent speed restriction

Permanent speed restrictions are imposed where the route encounters a hazard such as a tight radius curve, level crossings, certain junctions, tunnels and bridges. It is also called a slow zone. Permanent Speed Restrictions are those that represent maximum safe speed.

\section{SPEED MAP}

Based on the information collected from Bangladesh Railway on speed restriction on different lines a speed map is prepared and is shown in Figure 1. From the map, it can be seen that Parvatipur-Shantahar section has a maximum speed of $95 \mathrm{~km} / \mathrm{hr}$. This section has newly installed concrete sleeper, correctly aligned rails, uniform ballast formations and elastic fastenings. In contrast, Jamalpur- Tarakandi section has a maximum speed of 30 $\mathrm{km} / \mathrm{hr}$ due to having worn out steel sleepers and non-maintained rails. Similarly in Santahar-Parvatipur section, maximum allowable speed is $10 \mathrm{~km} / \mathrm{hr}$ due to severly damaged rails. But Poradaho-Pachuria section, despite of having wooden sleeper, has an allowable speed of $80 \mathrm{~km} / \mathrm{hr}$.

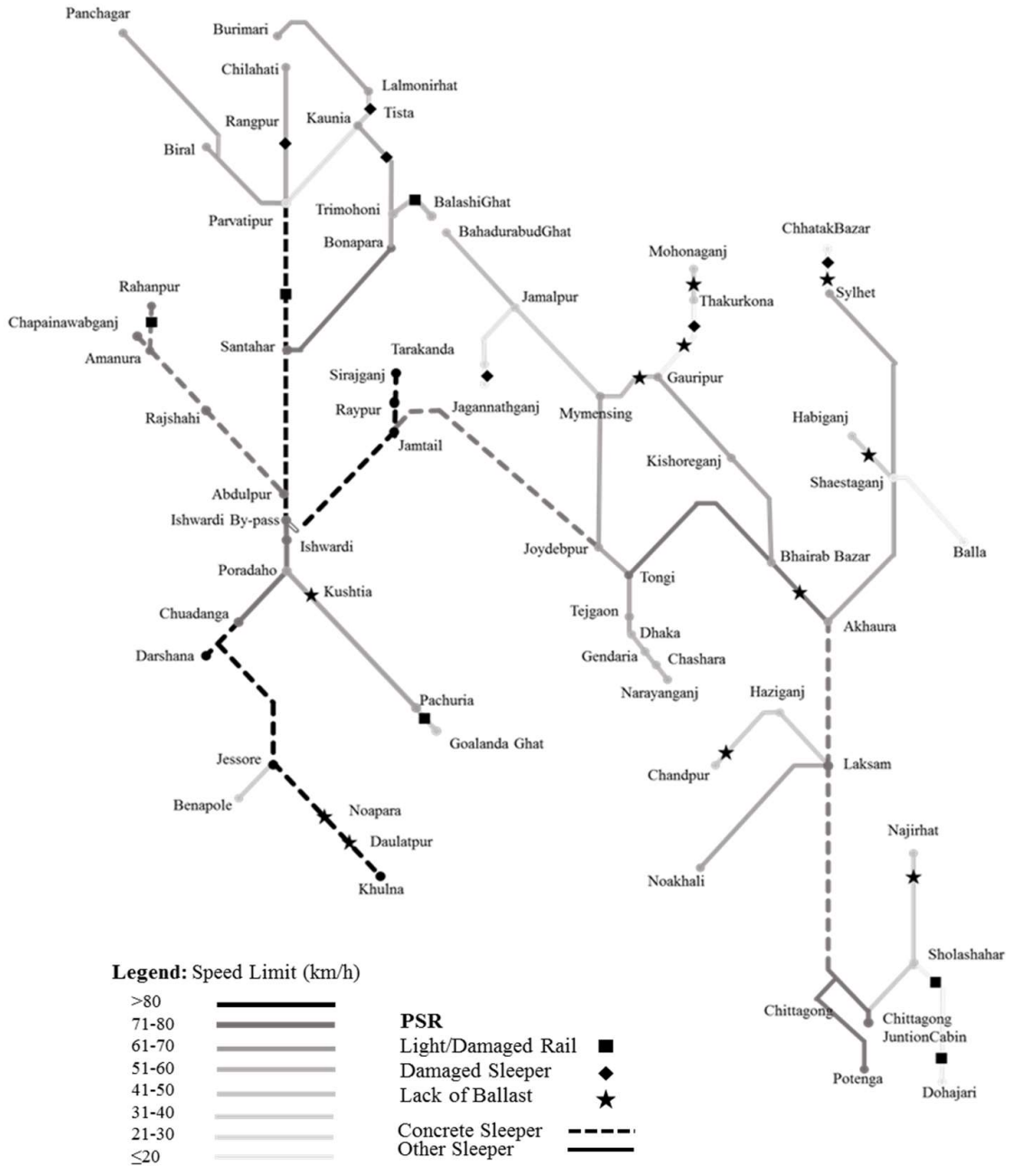

Figure 1: Bangladesh Railway Speed Restriction Program

\section{KEY IMPROVEMENT OPTIONS}

The accident problem can be corrected to a great extent by simple engineering techniques as well as by the enforcement of laws. In this respect some measures are suggested which may be considered to minimize the frequency and severity of accidents. 


\subsection{Accident Report Form}

There is a need for suitable refinement in present accident reporting criteria and data collection system. The present system of preparing accident report is time consuming and not ideal. Specific details of accident location, track, signal, interlocking, and vehicle condition are not mentioned. The exact time of accident and types of vehicles involved in each accident should also be recorded properly.

\subsection{Track Maintenance}

Accident data shows that track condition is responsible for maximum number of accidents. Rehabilitation is therefore, needed for tracks and bridges (Ahsan et al., 2016). The conventional method of track maintain by human resource are still in practice. More sophisticated track maintain arrangements such as, mechanical track lifting, slewing, tamping and laying machines should be used for track maintain. Moreover, maintenance work does not complete on schedule time because of administration complicity and lack of budget. So, the administration complicity should be eliminated and as well as budget is needed to be increased.

\subsection{Modernization of the Signalling System}

Modernization of the signalling system using colour lights and relay interlocking should be done to minimize the incidence of accidents particularly on account of human failure (Ahsan and Biswas, 2015). Such improvements also have the potential of increasing the line capacity.

\section{CONCLUSIONS}

Train accident data of Bangladesh Railway revealed that accident reporting and analysing system should be improved for fruitful detailed engineering based investigation and derailments are the major concern in railway safety. Rehabilitation and modernisation of the track network, signalling and rolling stock are needed for safe running of the Bangladesh Railway. However, as a safety approach against derailments Bangladesh Railway has taken rail track rehabilitation projects as well as speed restriction programs. 2015-16 data showed benefit of such restriction program.

\section{REFERENCES}

Agarwal, A., 2005. Rail Accidents due to Human Errors, Indian Railways Experience, International Railway Safety Conference, Cape Town, South Africa.

Agarwal, M.M., 2007. Indian Railway Track. Design, Construction, Maintenance \& Modernization, 15th Revised \& enlarged edition.

Ahsan, H.M., Rahman F. and Hayder T., 2016. Rail Connectivity in Bangladesh: Present and Future, Proceedings of the 3rd International Conference on Advances in Civil Engineering 2016 (ICACE-2016), 21-23 December 2016, CUET, Chittagong, Bangladesh.

Ahsan, H.M. and Islam A., 2015. Relation between Components of Permanent Way and Railway Speed in Bangladesh, Proceedings of the International Conference on Recent Innovation in Civil Engineering for Sustainable Development (IICSD-2015), Department of Civil Engineering, DUET, Gazipur, Bangladesh.

Ahsan, H.M. and Biswas P.K., 2015. Computer Based Interlocking: A New Era in Bangladesh Railway Signalling System, Proceedings of the International Conference on Recent Innovation in Civil Engineering for Sustainable Development (IICSD-2015), Department of Civil Engineering, DUET, Gazipur, Bangladesh.

Ahsan, H.M., Azzacy M.B. and Islam M.S., 2014a. Key Issues of Rail Safety in Bangladesh, Proceedings of the 2nd International Conference on Advances in Civil Engineering 2014 (ICACE-2014), 26-28 December 2014, CUET, Chittagong, Bangladesh.

Ahsan, H.M., Islam M.S. and Azzacy M.B., 2014b. Significance of Derailments in Rail Safety in Bangladesh, Proceedings of the 2nd International Conference on Civil Engineering for Sustainable Development (ICCESD), 14 16 February 2014, KUET, Khulna, Bangladesh.

Ahsan, H.M., Azzacy M.B. and Islam M.S., 2014c. Rail Safety at Level Crossings in Bangladesh, Proceedings of the 2nd International Conference on Civil Engineering for Sustainable Development (ICCESD), 14 16 February 2014, KUET, Khulna, Bangladesh.

Arora, S.P. and Saxena S.C., 2006. A Text Book of Railway Engineering, 7th edition, New Delhi, Ish Kanpur. Bangladesh Railway, 2009-2016. Bangladesh Railway Information Book 2009 to 2016.

Bangladesh Railway, 2016. Bangladesh Railway Timetable 2016.

Barkan, C.P.L., Dick C.T. \& Anderson R.T., 2003. Railroad Derailment Factors Affecting Hazardous Materials Transportation Risk, Transportation Research Record, No. 1825.

Brabi,e D., 2005. On the Influence of Rail Vehicle Parameters on the Derailment Process and its Consequences. 
Godward, E.W., 1992. The Future of Passenger Railways, Planning Passenger Railways, Edited by Harris, N.G. and Godward, E.W., Transport Publishing Co Ltd, Glossop, Derbyshire, England, January 1992.

Rail Safety New Zealand, 2011.Website: www.railsafety.co.nz/approach.html.

Wu, H., and Wilson N., 2006. Railway Vehicle Derailment and Prevention, pp. 209-237.

(C) 2021 the Authors. Journal of Engineering Science published by Faculty of Civil Engineering, Khulna University of Engineering \& Technology. This is an open access article under the terms of the Creative Commons Attribution-NonCommercial-NoDerivatives License, which permits use and distribution in any medium, provided the original work is properly cited, the use is non-commercial and no Modifications or adaptations are made. 